\title{
Mekansal tasarımda doğadan esinlenme: Armadillo'dan acil durum barınağına dönüşüm
}

\section{Inspiration by nature in spatial design: transformation from Armadillo to an emergency shelter}

\author{
Rumeysa KESKiN ${ }^{1}$, Latif Gürkan KAYA ${ }^{2}$ (1) , Cengiz YÜCEDAĞ ${ }^{2}$ \\ ${ }^{1}$ Burdur Mehmet Akif Ersoy Üniversitesi, Fen Bilimleri Enstitüsü, BURDUR \\ ${ }^{2}$ Burdur Mehmet Akif Ersoy Üniversitesi, Mühendislik Mimarlık Fakültesi, Peyzaj Mimarlığı Bölümü, BURDUR
}

Eser Bilgisi / Article Info

Araştırma makalesi / Research article

DOI: 10.17474/artvinofd.886369

Sorumlu yazar / Corresponding author Cengiz YÜCEDAĞ

e-mail: cyucedag@mehmetakif.edu.tr

Geliş tarihi / Received

24.02.2021

Düzeltme tarihi / Received in revised form

09.03.2021

Kabul Tarihi / Accepted

10.03.2021

Elektronik erişim / Online available

12.05.2021

\section{Anahtar kelimeler:}

Acil Durum Barınağ

Armadillo

Biyomimikri

Doğadan Esinlenme

Mekansal Tasarım

\section{Keywords:}

Emergency Shelter

Armadillo

Biomimicry

Inspiration by Nature

Spatial Design

\begin{abstract}
Özet
Bu çalışmanın temel amacı, mekansal tasarımlarda doğadan esinlenme bilincini artırmaktır. Günümüzde çok önemli olan sürdürülebilirlik kavramı ve onun öneminin anlaşılması ile tasarım kriterleri sıralanırken doğadan esinlenen tasarım ilkelerinin düşünülmesi hedeflenmektedir. Sorgulamanın artması ile birlikte çevresel döngüyü destekleyen en azından doğa ile uyumlu mekân tasarımlarının artışı sağlanmalıdır. Bu amaçlar doğrultusunda, zırhlı bir memeli olan armadillonun üç bantlı savunma mekanizmasından esinlenerek bir acil durum barınağı tasarım çalışması yapıımıştır. Bu çalışmada öncelikle acil durum barınaklarının fonksiyonel özellikleri ile ilgili literatür incelenmiştir. Böylece, bu tür yapıların depolanmasında ve taşınmasında hafiflik ve az yer tutmanın çok önemli olduğu anlaşılmıştır. Ayrıca, çalışmada armadillonun koruma sisteminden esinlenerek acil durum barınakları için çözüm önerileri geliştirilmiş ve tasarım süreci tamamlanmıştır.
\end{abstract}

\begin{abstract}
The main purpose of this study is to increase the awareness of inspiration by nature in spatial designs. With the understanding of the concept of sustainability and its importance, which is very important today, it has been aimed to consider the design principles inspired by nature while listing the design criteria. With the increase of questioning, at least the increase of spatial designs in harmony with nature supporting the environmental cycle should be provided. For these purposes, a conceptual design of emergency shelter was carried out through inspiration by the three-banded defense mechanism of the armadillo, an armored mammal. In this study, literature regarding the functional characteristics of emergency shelters was initially reviewed. Thus, it was found out that lightness and less spatial footprint were very important in the storage and transportation of such structures. In the study, solution proposals were also developed for emergency shelters through inspiration by the defense system of the armadillo, and the design process was completed.
\end{abstract}

\section{Giriş}

Dünya'da nüfus yoğunluğunun her geçen gün hızla arttığı düşünüldüğünde, enerji kullanımı, sürdürülebilirlik, geri dönüşüm gibi kavramların önemi giderek artmaktadır. İnsanların tasarımda karşılaştığı her sorunla, dünyada bulunan 30 milyon canlının karşılaşmış ve bu sorunlara verimli çözümler bulmuş olma olasılığı insanlara göre oldukça yüksektir.

Doğa büyük bir düzen içerisinde sürdürülebilir hayatlar ve mekanlar oluşturmaktadır. Doğa güvenilirdir, gerektiği kadar enerji harcar, çöp oluşturmaz, ciddi bir geri dönüşümcüdür. Bu yüzden mekansal tasarımların verimli, hafif, sürdürülebilir olması için, yeni tasarım ilkeleri belirlenmeli ve bu tasarım ilkeleri belirlenirken doğadan esinlenmek gereklidir.

İnsanoğlu varoluşundan bugüne korunma, barınma, estetik ve benzeri kaygılarla mekan oluşturmaya devam etmiştir. İnsanın doğayı düşündüğü bir düşünceyi düşünmek, doğanın bir model, bir ölçü ve bir rehber olduğunu kabul etmenin en kısa yoludur (Benyus 1998, Kaya ve ark. 2018).

Tasarımın her alanında olduğu gibi mekan tasarımında da tasarımcılar doğadan ilham almış ve doğayı taklit etmişlerdir. Doğadan esinlenilen mekansal tasarımlara bakıldığında literatürdeki en yaygın model, doğadaki form 
ve strüktürlerin benzeşimi ile yapıya aktarılması olmuştur (URL-1 2016).

Biyomimikri, Latince bios (hayat) ve mimikos (taklit) kelimelerinden türemiştir (Volstad ve Boks 2012, Kaya ve ark. 2018). Kennedy (2004)'ye göre biyomimikri aslında hayat ve doğayı taklit etmek üzere doğadan ilham alan tasarımdır. Biyomimikri terimi ilk olarak 1962'de bilimsel literatürde yer almış ve özellikle 1980'lerde yaygınlaşmaya başlamıştır (Aziz ve El Sherif 2015). Biyolog ve biyomimikrinin yaratıcısı Janine Benyus: Innovation Inspired by Nature (Doğadan ilham alan İnovasyon) adlı kitabında biyomimikriyi, "Yaşamın dehasının bilinçli öyküsü" olarak tanımlamıştır (URL-2 2018).

Doğanın derinliklerine bakıldığında, tüm insan icatlarının, daha zarif biçimlerde de olsa, gezegende çok daha düşük bir maliyetle zaten mevcut olduğu fark edilmektedir. En akıllı yapı sistemlerinden biri olan kolon ve kirişlerin kullanılması, zambakların içyapısında ve bambu saplarında yer almaktadır. En iyi insan yapımı sonar çok frekanslı yarasaların iletimleriyle karşılaştırıldığında duymak zordur. Her zaman benzersiz bir insan oluşumu gibi görünen çark bile, dünyadaki en eski bakterilerin kamçılarını harekete geçiren küçük döner motorda bulunmuştur (Benyus 1998).

Biyomimikrinin amacı, dünyadaki yaşamı sürdürmek için iyi adapte olan ve yaşam tarzımıza yenilikçi gelişmeler sağlayan ürünler, süreçler ve politikalar yaratmaktır. Bunun için de, aşağıdaki konularda yardımcı olmayı hedeflemektedir (Akgöze 2015):

- Sürdürülebilirlik

- Performans iyileştirme

- Enerji Korunumu

- Maliyetleri azaltma

- "Çöp" kavramını yok etmek ve yeniden tanımlamak

Biyomimikri, tasarım ve tasarımcıyı sürece dahil ederek doğadan ilham alarak yaratıcı çözümler geliştirmeyi hedefler. Doğa'nın 3,8 milyar yıllık tecrübesini artık mevcut araçlar ve yeteneklerle inceleyebilme olanağı artmıştır (Volstad ve Boks 2012). Günümüzde enerji verimliliğine ve sürdürülebilirlik gibi kavramlara verilen önem de doğaya dönüşü açıklamaktadır. Bu alanda önemli çalışmalar yapan Benyus (1998), biyomimikriyi insanların sorunlarına çözüm bulmak adına doğanın modellerini inceleyen, taklit eden ve ilham alan yeni bir bilim olarak ifade eder. Bu doğrultuda doğanın tasarımlarında 9 temel özellik sıralar (Eryılmaz 2015):

- Doğa güneş ışığından yararlanır

- Sadece gereksinim duyduğu enerjiyi kullanır

- Işleve uygun şekil yaratır

- Herşeyi geri dönüştürür

- İşbirliği ile gelişir

- Çeşitliliğe dayanır

- Yerel unsurlardan faydalanır

- Fazlalıkları uzak tutar

- Sinırları zorlar

Benyus (1998)'a göre, hasat ya da evcilleştirme yerine, biyomimetik organizmalara danışmak; fiziksel bir plan, kimyasal tepkimede bir süreç aşaması veya besin döngüsü gibi bir ekosistem ilkesi fikrinden ilham alınmasını sağlar. Bu üç temel yaklaşım - form, davranış ve ekosistem biyomimetik inovasyonu kategorize etmek için kullanılabilir. Form, bir bitki veya hayvan gibi spesifik bir organizmaya atıfta bulunur ve tüm organizmanın bir kısmını ya da tamamını taklit etmeyi içerir. İkinci seviye, davranışı taklit etmek anlamına gelir ve bir organizmanın nasıl davrandığıyla ilgilidir. Üçüncü seviye, tüm ekosistemlerin taklit edilmesi ve onların başarılı bir şekilde işlev görmesine izin veren ortak ilkelerdir (Zari 2007).

Form biyomimikrisi örneği; Namibya çöl böceği çok az yağış alan bir çölde yaşamaktadır. Bununla birlikte, rüzgara karşı vücudunu yan yatırarak sisteki nemi yakalayabilmektedir. Böceğin kabuğunun su seven ve su tutmayan yapıları sayesinde sırt ve kanatları üzerinden su damlaları ağzına yuvarlanır (Parker ve Lawrence 2001). Tasarımcının Namibya Üniversitesi Hidroloji Merkezi için önerdiği sis yakalayıcı tasarımı Namib böceğinden etkilenen organizma düzeyinde süreç biyomimikliğini göstermektedir (Şekil 1). Knight (2001) ve Ravilious (2007) organizma düzeyinde biyomimikri hakkında tartışmakta; böylelikle böceğin yüzeyinin incelendiği ve hava pistlerinden sisi temizlemek ve nem alma ekipmanını iyileştirmek gibi diğer potansiyel uygulamalar için kullanılmak üzere taklit edildiği görülmektedir (Zari 2007). 

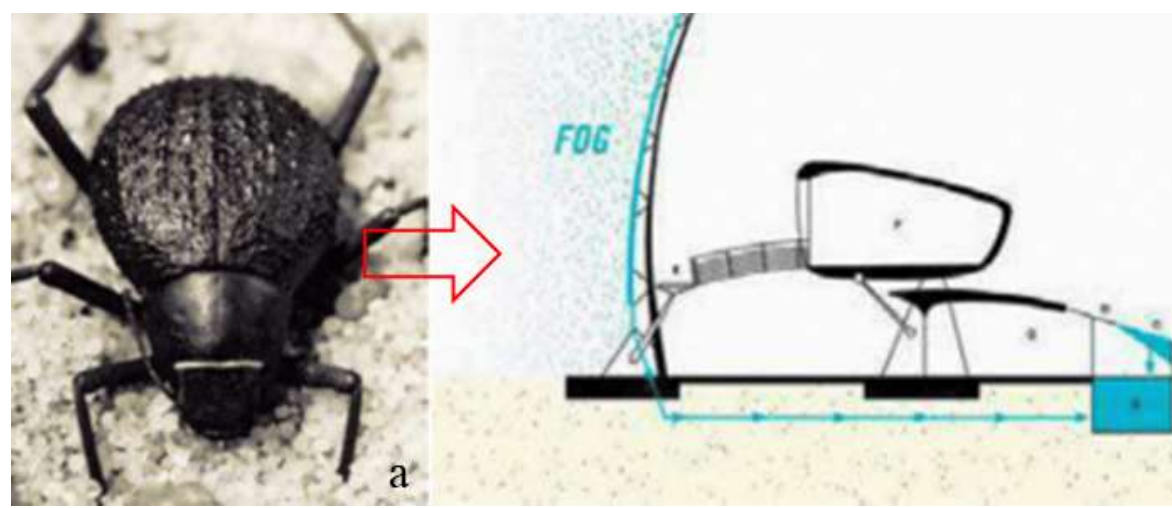

$\mathrm{b}$

Şekil 1. a) Stenocara böceği, b) Namibya Üniversitesi Hidroloji Merkezi, Windhoek, Namibya (Boğa 2013)

Kuzey Amerika kunduzunun (Castor canadensis) (Şekil 2) çalışma örneği davranış biyomimikrisine örnektir. Peyzajı değiştirerek sulak alanların nasıl oluşturulduğunu ve besinlerin tutulmasının ve bitki ve hayvan çeşitliliğinin nasıl arttırıldığını gösterir ve kısmen ekosistemin rahatsız edilmesine karşı daha esnek hale gelmesini sağlar (Rosemond ve Anderson 2003). Davranış düzeyinde biyomimiklikte, taklit edilen organizmanın kendisi değil davranışıdır. Davranış seviyesindeki süreç ve fonksiyon biyomimikrisinin mimari bir örneği kuzey Amerika

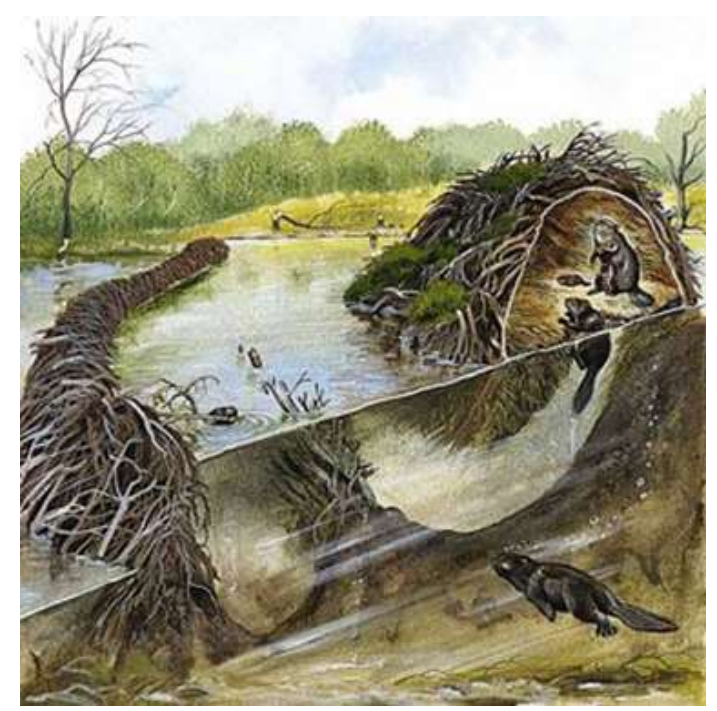

Şekil 2. Kuzey Amerika Kunduzu (URL-3 2015)

Ekosistem biyomimikrisinin bir örneği, Mithūn Architects ve GreenWorks Peyzaj Mimarlığı danışmanlarını içeren bir tasarım ekibi tarafından Portland, Oregon için önerilen Lloyd Crossing Projesidir (Şekil 4). Proje, gelişimden önce şantiyede var olan ekosistemin nasıl işlediğini görmek, kunduzundan esinlenilerek tasarlanan Avustralya'nın Melbourne kentindeki $\mathrm{CH} 2$ binasıdır (Şekil 3). Bina kısmen termal olarak kararlı bir iç ortam oluşturmak için termit höyüklerde gözlemlenen pasif havalandırma ve sıcaklık düzenleme tekniklerine dayanmaktadır. $\mathrm{CH} 2$ binasının altındaki kanalizasyonlardan çıkan ve temizlenen su, belirli termit türlerinin buharlaştırıcı soğutma mekanizması olarak akifer suyunun kullanımına benzer bir şekilde kullanıı (Zari 2007).

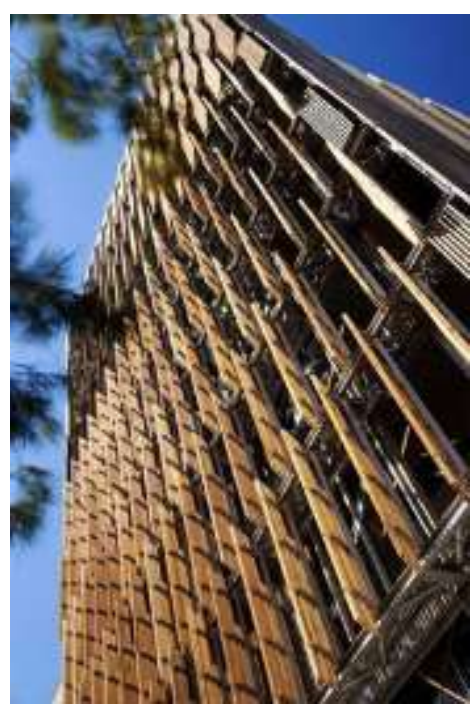

Şekil 3. $\mathrm{CH} 2$ Binası Melbourne, Avustralya (URL-4 2019)

projenin uzun süre boyunca ekolojik performansına yönelik hedefler belirlemek için "Ön Geliştirme Metrikleri" olarak adlandırdığı tahminleri kullanır (Zari 2007). 


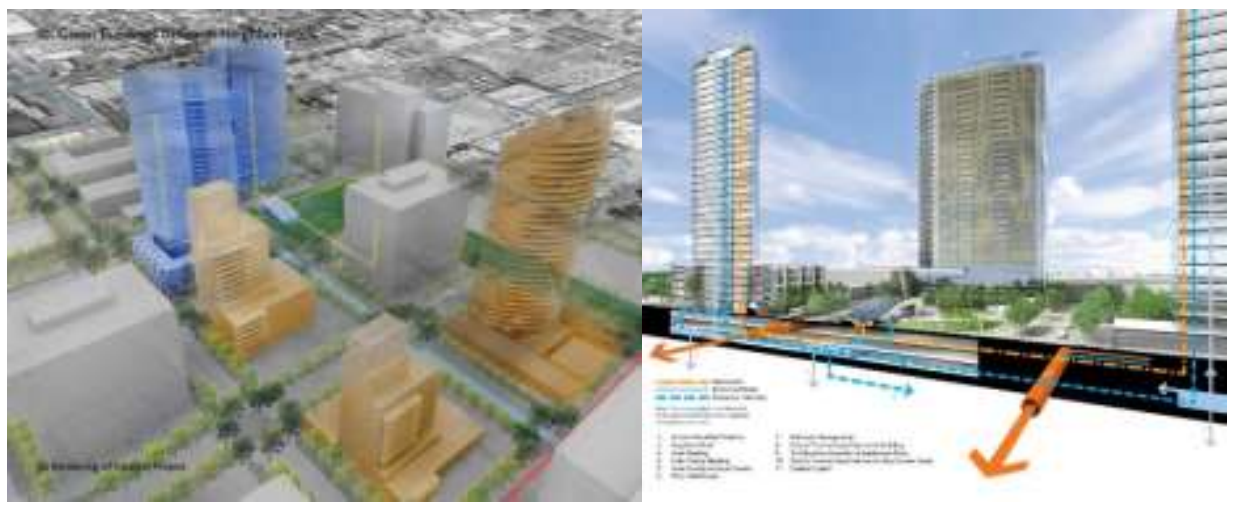

Şekil 4. Lloyd Crossing Projesi, Portland, ABD (URL-5 2019)

Günümüzde tüm bilimler için bir rehber olan, doğanın taklidi ve gözlemlenmesiyle ilerleme kaydeden biyomimikri mekan tasarımlarında da bizi etkilemektedir (Tokman 2012). Benyus (1998)'a göre doğadan esinlenmenin mekan tasarımlarında üç temel uygulama alanı vardır:

- Daha dayanımlı, güçlü ve kendi kendine birleşebilen ve kendi kendini onarabilen malzemelerin geliştirilmesi,

- Binaların ve yapılı çevrenin iklimlendirilmesinde doğal süreç ve kuvvetlerin kullanılması,

- Enerji korunumlu ve çevrimli, atıkların tekrar kullanılmasına olanak veren, kaynakları tüketerek değil kaynak üreterek yapılı çevrelerin oluşturulması doğadan esinlenme ile mümkündür.

Vincent (2005)'e göre, bir tasarımda doğadan esinlenildiğinde bazı biyolojik özelliklere de sahip olması gerekmektedir. Bu, bir tasarımda doğadan esinlenmenin sadece biçim ve formla kısıtlı kalmayıp, problemlere nasıl çözüm bulduğuna bakarak daha etkili olabileceği anlamına gelmektedir. Bir tasarım süreci olarak biyomimikriyi kullanmak iki şekilde ilerleyebilir (Zari 2007):

- Biyolojiden Esinlenen Tasarım

- Tasarımı Etkileyen Biyoloji

Bunlardan ilki bir insan gereksinimi veya tasarım probleminin tanımlanması ve diğer organizmaların veya ekosistemlerin bunu çözme biçimlerine bakmaktır. Burada biyolojiye bakmak, belirli bir özelliği, davranışı, işlevi tanımlamak organizmayı veya ekosistemi insan tasarımlarına dönüştürmek, biyoloji etkileyen tasarım olarak adlandırıır (Zari 2007).

Biyolojiden esinlenen tasarıma örnek olarak otomotiv endüstrisinin aerodinamik sorunu aşabilmek için kutu balığından (Ostracion cubicus) faydalanması örneklenebilir (Şekil 5)

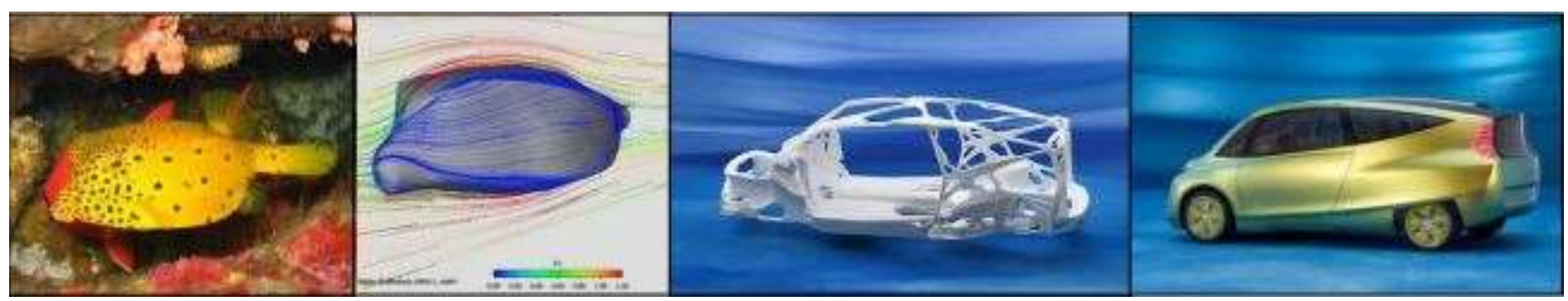

Şekil 5. Kutu balığından esinlenen biyonik otomobil (Zari 2007)

Biyonik araba yakıt kullanımı açısından daha verimlidir, çünkü kutu balıkların taklit edilmesinden dolayı vücut daha aerodinamiktir. Aracın yapısındaki minimum malzeme ihtiyacını tespit etmek için ağaç büyüme desenlerinin taklit edilmesi nedeniyle daha fazla materyal etkin olmaktadır (Zari 2007). 
Boya sanayisinde ise su tutmayan ve kirlenmeyen boya yüzeylerinin oluşturulmasında lotus çiçeğinden faydalanılması tasarımı etkileyen biyolojiye örnektir (Altun 2011, Primlani 2013).

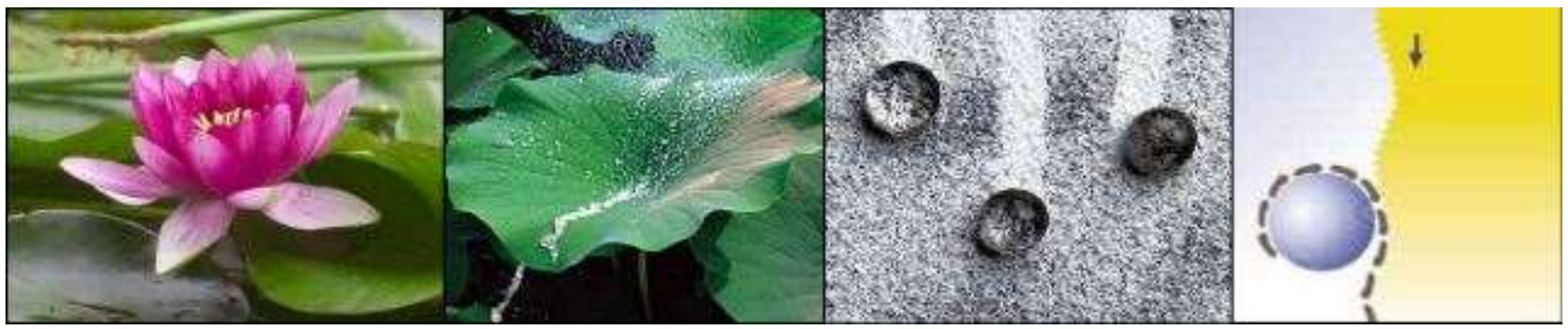

Şekil 6. Lotustan ilham alan lotusan boyası (Zari 2007)

Bataklık sularından temizlenen nilüfer çiçeğinin (Nelumbo $s p$.$) bilimsel analizi tasarımların kendi kendini$ temizlemesini sağlayan Lotusan boyası dahil olmak üzere birçok tasarım inovasyonuna yol açmıştır (Şekil 6) (Zari 2007).

Zari (2007)'nin çalışmasına benzer şekilde Ali El-Zeiny (2012)'nin çalışmasında da bir tasarım süreci olarak biyomimikri yaklaşımı iki kategoriye ayrılır:

- Probleme dayalı yaklaşım (Yukarıdan Aşağıya Yaklaşım)

- Çözüme dayalı yaklaşım (Aşağıdan Yukarıya Yaklaşım)
Probleme dayalı yaklaşım Zari'nin çalışmasında biyolojiden esinlenen tasarım diye adlandırdığı yaklaşım, çözüme dayalı yaklaşım ise Zari'nin çalışmasında tasarımı etkileyen biyoloji diye adlandırdığı yaklaşımdır (Ali ElZeiny 2012).

Probleme dayalı yaklaşım modeli, uygulamada sonraki aşamalardan çıkarılan sık sık önceki aşamaları etkileyen, yinelemeli geri besleme ve inceltme döngüleri sağlayan, doğrusal olmayan ve dinamik olan adımların ilerlemesini izler (Helms ve ark. 2009). Georgia Teknoloji Enstitüsü Tasarım İstihbarat Laboratuarı'nda yapılan araştırmalar, probleme dayalı yaklaşımı 6 kesin adımda tanımlamıştır (Şekil 7) (Helms ve ark. 2009, Ali El-Zeiny 2012)

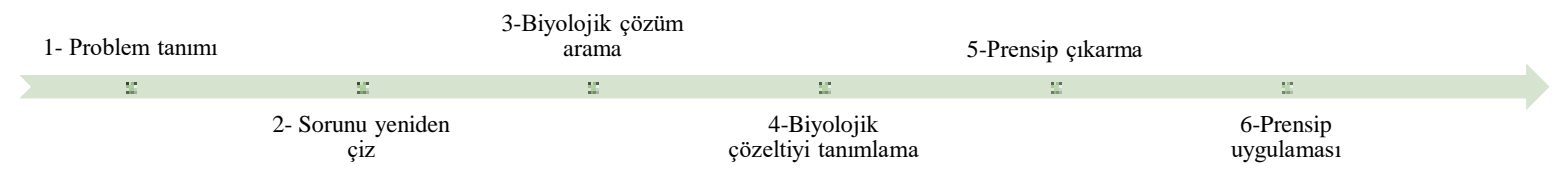

Şekil 7. Probleme dayalı yaklaşımın adımları

Georgia Teknoloji Enstitüsü, Tasarım İstihbarat Laboratuarı'nda çözüme dayalı yaklaşım, 7 kesin adımda tanımlanmaktadır (Şekil 8) (Ali El-Zeiny 2012).

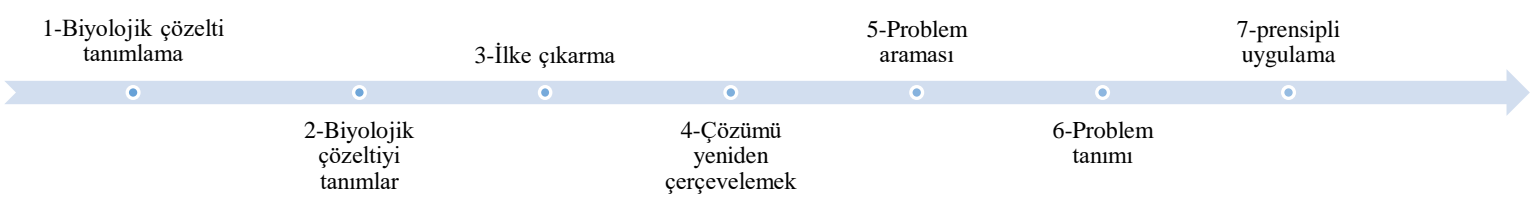

Şekil 8. Çözüme dayalı yaklaşım adımları

Biyomimikrinin doğada bulunan yaşamın ilkeleri, varlığını sürdüren ve gelişen organizmalar arasındaki koşulları temsil etmektedir (Baumeister 2013). Tasarımcılar hayatın pozitif yaşam koşulları yarattı̆̆ını anlarsa, sürdürülebilir ortamlarda sürdürülebilir tasarımlar yapmak mümkün olacaktır (Benyus 2002). Bu koşulları 
öğrenmek ve anlamak, daha etkili bir şekilde korunabilecek mekanlar ve ortamlar yaratabilir. Bu adımlar izlenirse, tasarımcılar doğanın dehasına yönlendirilebilir. Bu ilkelerden birinin ihmal edilmesi veya uygulanmaması durumunda, tasarım eksiktir ve biyomimetik amaç silinir. Bu ilkeler Şekil 9'da gösterildiği gibidir (Baumeister 2013, Karabetça 2015).

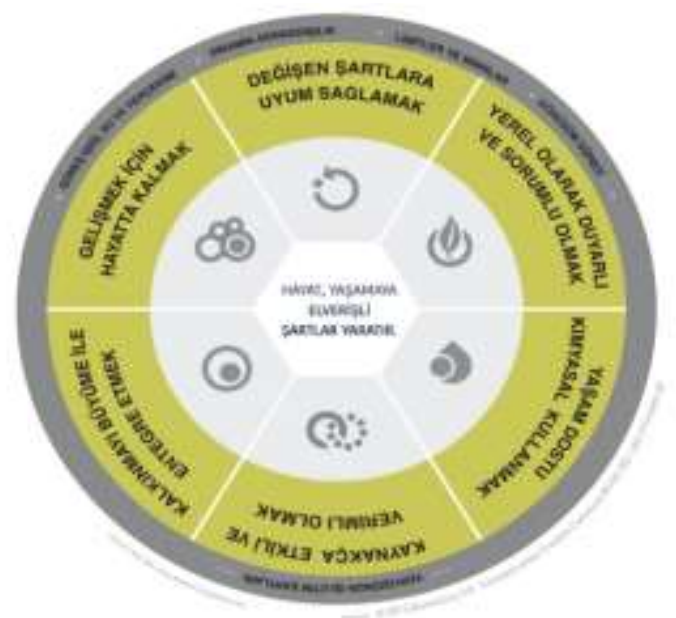

Şekil 9. Biyomimikri Tasarım Merceği: Yaşam ilkeleri (Baumeister 2013)

Bu ilkelere göre, tasarlanan mekanlar, binalar ve ortamlar sürdürülebilir yaşam tarzları elde ederken daha yaşanabilir olacaktır. Enerji verimliliği, kendi kendini temizleyen malzemeler, su toplama cepheleri, enerji tasarruflu aydınlatma sistemleri, güçlü yapılar vb. tasarımlar için biyomimikri ideal ve sürdürülebilir bir çözüm olarak tanımlanmalıdır.

\section{MATERYAL VE YÖNTEM}

Biyomimikri tasarım süreci, ön tasarım ve taklit olmak üzere iki aşamadan oluşmaktadır. İlk aşama problemin tanımı ve organizmaların, doğal sistemlerin incelenmesini içerir. İlk aşamadan sonra elde edilen bilgilerin çözüme dönüştürülmesi teknolojik ve biyolojik bilgi gerektiren karmaşık bir süreçtir (Öztoprak 2018). Bu nedenle bu çalışmada kullanılan tasarım yaklaşımı ön tasarım aşamasındadır. Armadillodan esinlenilen bir acil durum barınağı tasarım çalışması yapılmıştır.

Araştırmanın ana materyalini armadillo ve acil durum barınakları oluşturmaktadır. Türkiye jeolojik yapısı ve sahip olduğu iklimsel özellikleri nedeniyle büyük can ve mal kayıplarına yol açan doğal afetlerle sık karşılaşmaktadır. Bu durum Türkiye'de acil durum barınaklarının önemini ortaya koymaktadır. Bu faktör örnek mekan tasarımı olarak acil durum barınaklarının seçilmesinde etkili olmuştur. Biyolojiden esinlenen tasarım yaklaşımıyla kısa bir literatür taraması yapıldıktan sonra, acil durum barınaklarının asgari kriterlerinden yola çıkılarak, armadillonun hareket kabiliyetinden esinlenilen bir barınak tasarlanmıştır.

Armadillo, keratinden yapılmış bir deri zırh kabuğu olan 12 ila 15 santim uzunluğunda bir memelidir. İspanyolcada armadillo "küçük zırhı" anlamına gelmektedir. Çünkü armadilloların koruyucu levhaları avcılara karşı ana savunma hattı olarak işlev görür (URL-6 2012).

Orta güney Amerika'da bulunan üç bantlı armadillo (Tolypeutes tricinctus), incelendiğinde sıkı bir top şeklinde kıvrılan tek armadillo türü olduğu görülmüştür (Şekil 10). Bu özelliği ona daha fazla hareket özgürlüğü sağlar. Gevşek kabuk aynı zamanda daha sıcak iklimlerde yaşayan armadilloların izole edilmesine yardımcı olur (URL-6 2012).

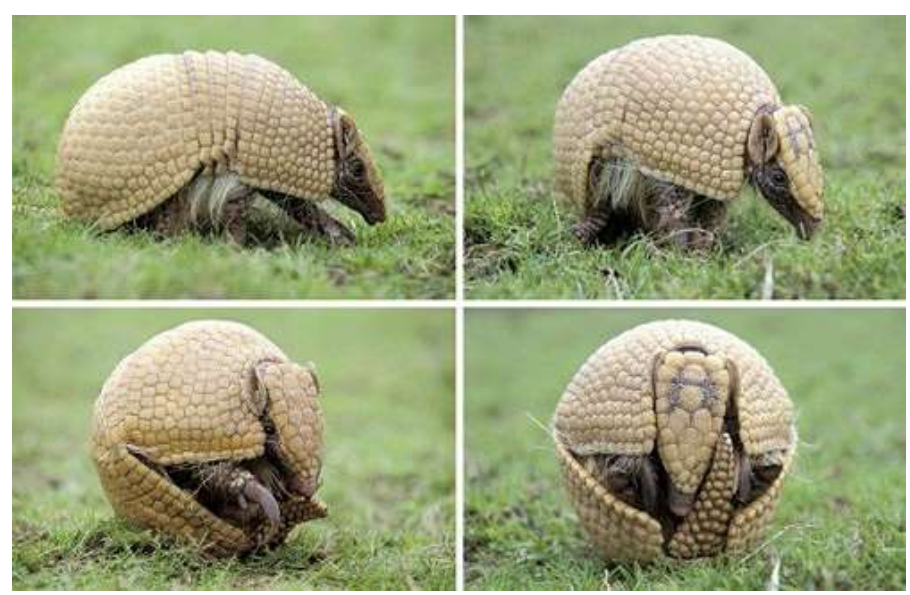

Şekil 10. Armadillo (Cingulata sp.) hareket özgürlüğü (URL-7 2016)

Şekil ekonomisi, kürenin yüzeyine bir çeşit esnek zırh kaplaması eklenerek daha da etkili hale getirilir. Tüm savunmasız ve hayati organlar ve uzuvlar koruyucu mahfaza içerisinde saklanır ve bir avcıya yemek yerine sinir bozucu bir top oyunu sunar (URL-8 2016). Hap böceğine benzer şekilde, armodillonun zırhı ve tehdit hissettiğinde onu dağıtma kabiliyeti, ilham kaynağıdır. Bu ilham, canlıların dış etkilerden korunmak için bir barınağa ihtiyaç duydukları düşünüldüğünde, herhangi bir tehlike 
tehdidi olmasa bile bir acil durum barınağı için de geçerlidir.

Barınma, insanlığın varoluşundan beri süregelen, insanoğlu için en temel intiyaçlardan biridir. Bu ihtiyacın karşılanması noktasında ise insanı tehlikeli derecedeki soğuk ya da sıcaktan koruyan, içinde dışarıya nazaran güvenli şekilde uyuyabileceği ve bazı ihtiyaçlarına cevap verebilen, içinde yaşanan yapı veya korunaklı yer olarak tanımlanan barınak yapıları devreye girer. Günümüzde ise, barınaklar, acil durumlar, doğal afetler ve zorunlu göçler sonucu ortaya çıkan barınma intiyacına cevap niteliği taşıyan mimari tasarımlar olarak karşımıza çıkar. Bu ihtiyaca cevap verecek olan tasarımın, barınağın yer alacağı bölgenin iklim şartlarına uygun olması, gerektiğinde uzun dönemler boyunca kullanılabilmesi, aynı zamanda da hızlı ve ucuza üretilebilmesi ve kolay uygulanabilmesi gerekmektedir. Acil durum barınakları, dönüştürülebilir malzemelerden oluşan, sökülüp veya taşınıp tekrar kullanılabilen yapılar olmalıdır (Altınkaynak 2016).

Acil durum evresinde kullanılabilecek barınak için kriterler aşağıdaki şekilde sıralanmaktadır (Sey ve ark. 1987);

- Afetten sonra, barınaklar kısa süre içinde kurulabilmelidir (Maksimum 1 gün içinde).

- Barınağın dış kabuğu ya da örtüsü zararlı dış etkilerden korunmayı sağlayabilmelidir.

- Barınaklar birden çok afet için kullanılabilmelidir.

- Tümüyle bitmiş olarak getirilmesi gerekmektedir.

- Hafif ve kolay taşınabilmesi gerekir.

- Kurulum işleri basit ve hızlı olmalıdır.

Acil durum barınaklarının depolanırken az yer kaplaması, kolay kurulabilir olması, hafif ama dayanıklı olması önemlidir. Bu gereksinimlerinden yola çıkılarak bir acil durum barınağı tasarlanmıştır. Tasarım aşamasında kapandığında mümkün olan en az yüzey alanına sahip olması için armadillonun hareket kabiliyetinden esinlenilmiştir.

Detaylı literatür taraması ve incelenen örnek tasarımlardan sonra, içeriğin ve amacın daha iyi anlaşılabilmesi için konsept bir tasarım çalışması yapılmıştır. Materyal olarak belirlenen armadillo ve acil durum barınağı hakkında literatür taraması yapılmıştır. Tasarım kriterleri belirlendikten sonra armadillodan esinlenerek modüler bir acil durum barınağ tasarlanmıştır. Öncelikle armadillonun kabuk yapısından yola çıkılarak acil durum barınağı için eskiz çalışmaları yapılmıştır. Nihai tasarıma karar verildikten sonra 3D modellemesi için Sketchup programında yapılmış, Keyshot programında render alınmıştır. Renderlar üzerindeki düzeltmelerde Photoshop programından yararlanılmıştır.

\section{BULGULAR VE TARTIŞMA}

Yapılan araştırmalar doğrultusunda bir acil durum barınağı tasarım çalışması yapılmıştır. Doğadan esinlenilen tasarım ölçütleri ile ortaya konacak mekan konsept olarak tasarlanmıştır. Tasarlanan acil durum barınağı modülerdir. İstenilen bölgeye taşınmaya ve o bölgede kullanılmaya elverişlidir. Acil durum barınağ tasarımda doğadan esinlenen tasarım ilkelerinden yola çıkılarak, biyomimetik karakter kazandırılması hedeflenmiştir.

Acil durum barınağı kriterlerinden yola çıkılarak; hafif, dayanıklı, uzun ömürlü, pratik, kolay taşınan, kolay depolanan, az yer kaplayan bir acil durum barınağ tasarlanmıştır. Biyolojiden esinlenen tasarım yaklaşımıyla bu gereksinimlerden yola çıkılarak doğada çözüm olabilecek canlılar araştırılmıştır. Armadillonun dikkat çeken savunma mekanizması, kendini dış etkilerden koruması ve bunu sağlayan kabuk yapısı tasarlanan acil durum barınağı için ilham kaynağı olmuştur. Tasarım aşamasında armadillonun hareket kabiliyetinden ve dış kabuğundan esinlenilmiştir (Şekil 11). 

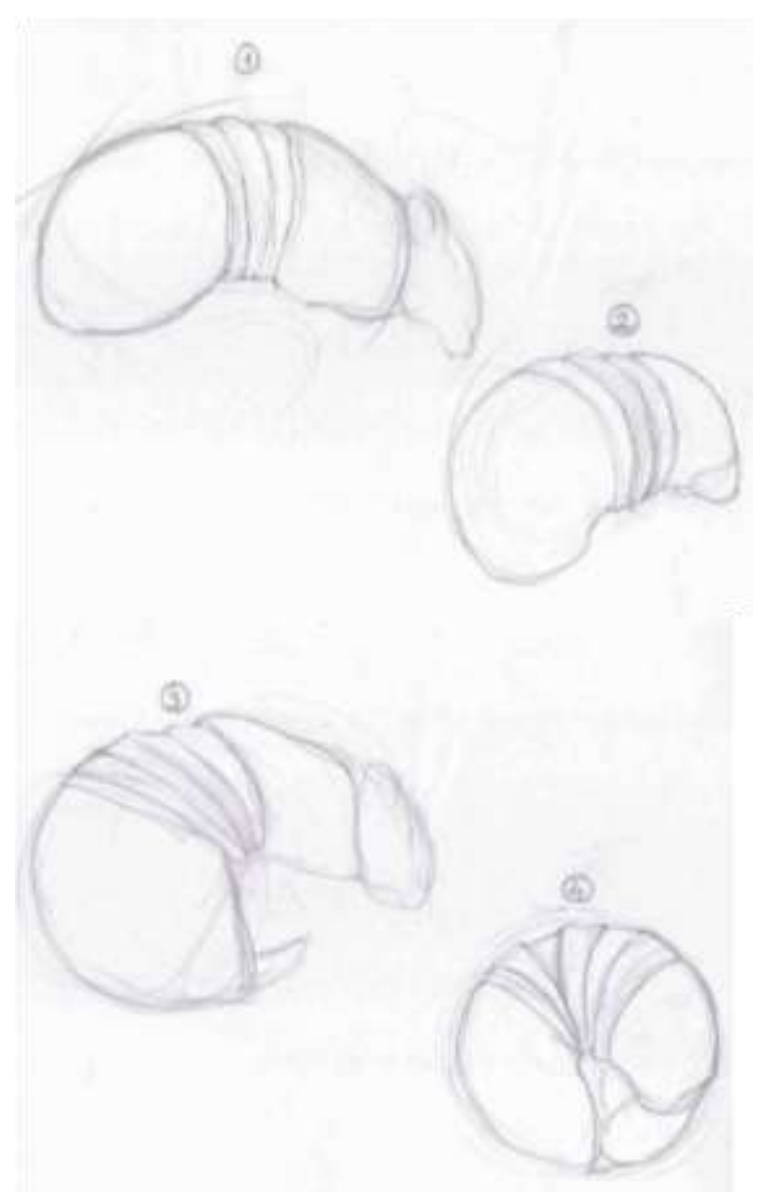

Şekil 11. Armadillonun yuvarlanarak kapanma aşamaları

Armadillonun kesitine bakıldığında yuvarlanarak kapanmasını sağlayan esnek dış kabuğunun baş kısmından itibaren birbiri üzerine geçen bölümlerden oluştuğu görülmektedir (Şekil 12).

Armadillonun birbiri üzerine geçen kabuk yapısı acil durum barınağı tasarımında düz bir zemin üzerinde kurulabilecek şekilde taklit edilmiştir (Şekil 13).

Acil durum barınağı 4-5 kişinin barınabileceği, bir kişinin tek başına rahatça kurabileceği ölçülerde tasarlanmıştır (Şekil 14).

Yapılan araştırmalar ve eskiz çalışmaları sonrasında acil durum barınağının 3 boyutlu modellemesi yapılmıştır (Şekil 15). Tasarım aşamasında sketchup ve keyshot programları kullanılmıştır. Modelde modüller iç içe geçebilmesi için tek tek ebatlandırılmıştır. İlk modül uzunluğu $215 \mathrm{~cm}$ olarak belirlenmiş, bu ölçü son modüle doğru giderek azalmıştır. Barınak açıldığında orta kısımda olan modül bir insanın rahatça ayakta durabileceği ölçüde $200 \mathrm{~cm}$ ve son modül $185 \mathrm{~cm}$ 'dir.
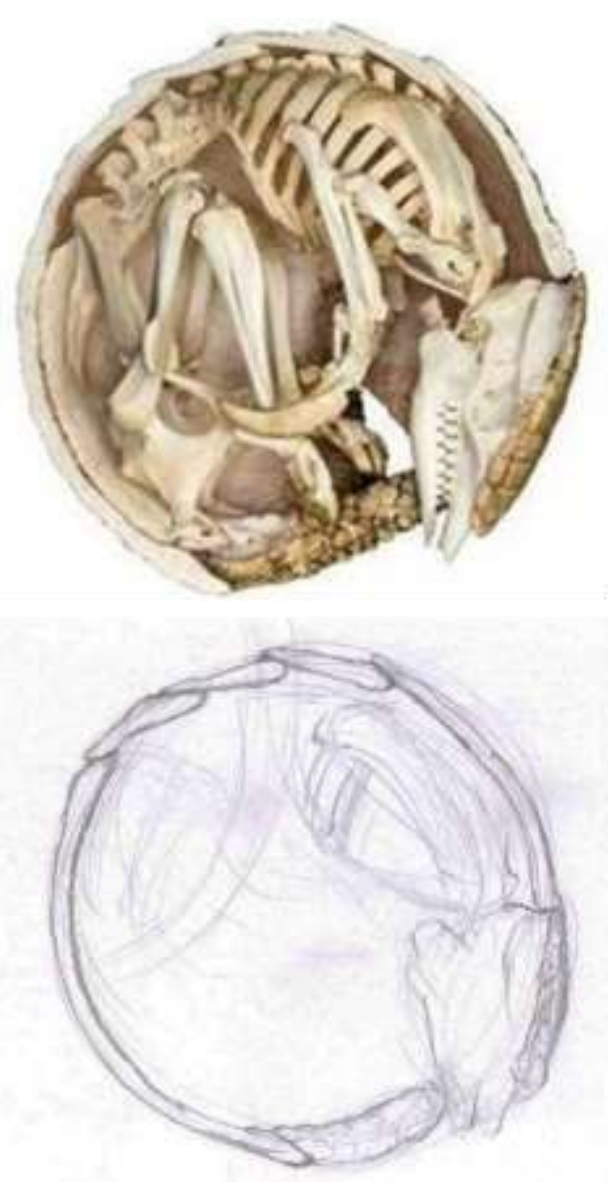

Şekil 12. Armadillo Kesit - Eskiz

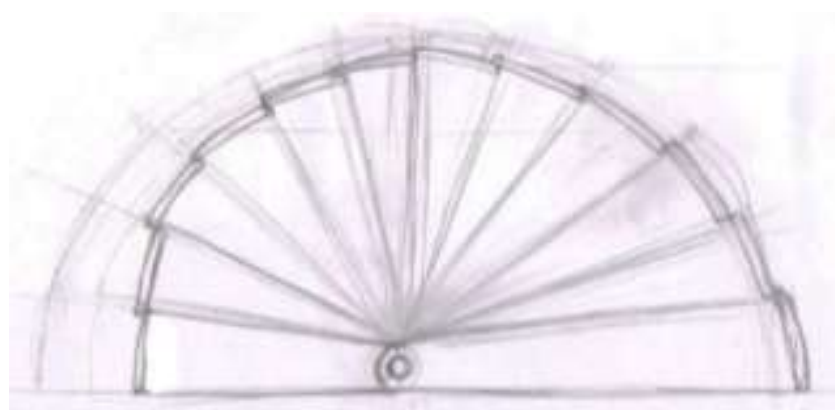

Şekil 13. Acil durum barınağı kesiti

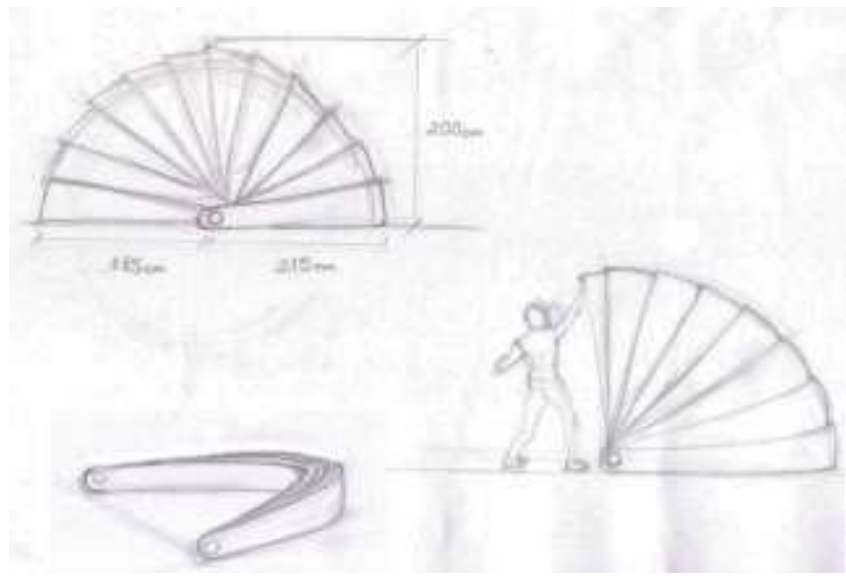

Şekil 14. Acil durum barınağı açılıp kapanması 


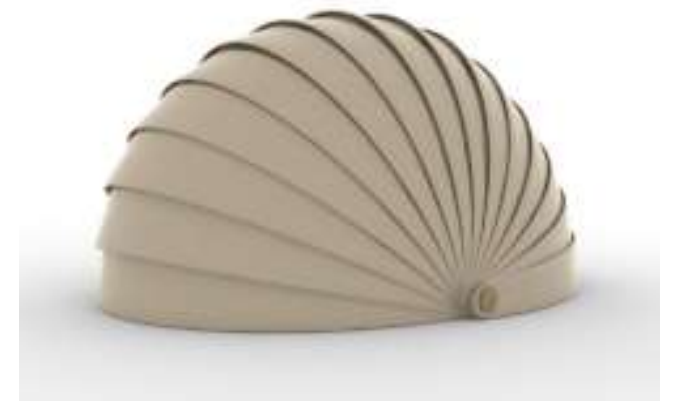

Şekil 15. Acil durum barınağı 3 boyutlu modeli

Barınak zeminde kullanıma hazır durumdayken $400 \times 300 \mathrm{~cm}$ yer kaplamaktadır. Yüksekliği $200 \mathrm{~cm}$ 'dir. Bu da yaklaşık 4-5 kişinin barınabileceği ebatlardadır. Armadillonun dış kabuğundan esinlenerek tasarlanan barınak kapanma özelliği sayesinde kapandığında $300 \times 215 \times 40 \mathrm{~cm}$ yer kaplamaktadır (Şekil 16). Kapandığında yüzey alanının olabildiğinde küçülmesi afet sonrasında pratiklik açısından çok önemlidir.

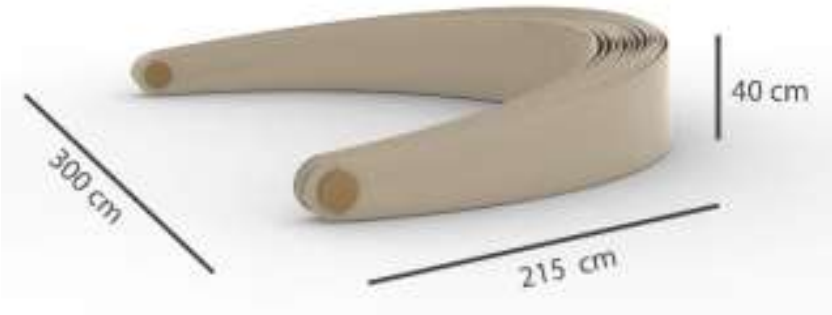

Şekil 16. Acil durum barınağı kapanmış hali

Barınağın tasarımında dayanıklı ama hafif olması için çelikten 5 kat hafif 10 kat güçlü olan karbon fiber malzemesi kullanılmıştır. Modüllerin hareket etmesini sağlayan ve bir arada tutan 2 adet bağlantı elemanı kullanılmıştır (Şekil 17).
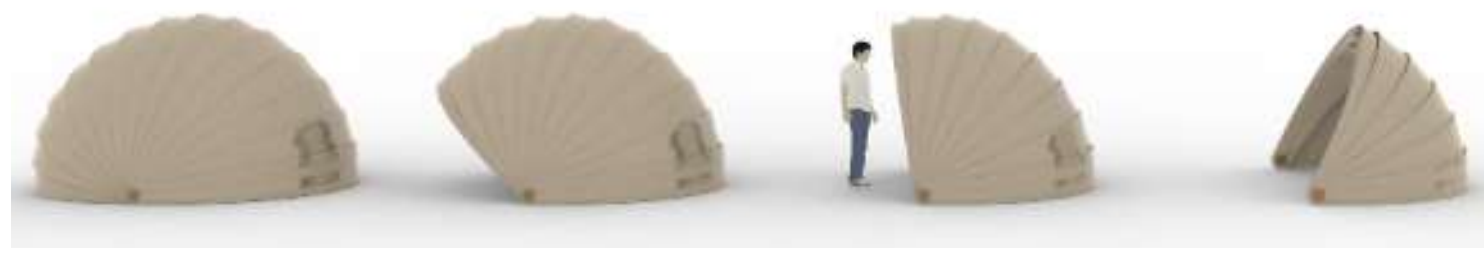

Şekil 17. Acil durum barınağının açılıp kapanması

\section{SONUÇLAR}

Bu çalışmada armodillodan esinlenilerek bir acil durum barınağı tasarlanmıştır. Konuyla ilgili literatür taraması yapılmış ve konsept bir proje tasarım çalışması hazırlanmıştır. Konsept bir çalışmanın tasarlanması ilkelerin daha iyi anlaşımasını ve tasarım sürecinin bir örnek üzerinden anlatılmasını sağlamıştır. Acil durum barınağı örneğinde olduğu gibi doğadan esinlenmek üzere başlanılan bir tasarım armadillo gibi doğadan bir örneğin bulunması ve incelenmesiyle süreci hızlandıracaktır.

Tasarımcıların karşılaştığı birçok sorunun çözümü doğada mevcuttur. İnsanoğlu doğadan esinlenmeden de problemlerine çözüm bulabilmektedir. Ancak biyomimikri ilkeleri ile tasarıma başlanacak olması yol gösterici olması anlamında önemlidir. Tasarımcının aradığı yolu bulmasını kolaylaştıracaktır.
Tasarım eğitimi sırasında doğadan esinlenme ve biyomimikri öğretilirse, bu konuda daha bilinçli tasarımcılar yetiştirilebilir. Biyomimikri destekli tasarıma yönelen tasarımcı etrafına farklı bir gözle bakmaya, canlıların hayatlarındaki incelikleri ve çözümleri fark etmeye başlayacaktır. Doğaya doğadan esinlenme için farklı bir gözle bakan tasarımcı aslında tasarımda karşılaşılan her problemin çözümünün doğada var olduğunu görebilecektir.

Artık sadece sürdürülebilir değil, aynı zamanda Dünya'daki yaşamın dokusunu destekleyen yenilenebilir ve onarıcı tasarımlar, malzemeler ve teknolojiler tasarlamak gerekmektedir. Bunun içinde biyomimikri hem form hem de fonksiyonel fikirler için tasarımlara dahil edilmelidir. 


\section{TEŞEKKÜR}

Bu çalışma, "Doğadan Esinlenen Mekansal Tasarımlarda Analojinin Kullanımı: Biyomimikri" başlıklı yüksek lisans tezi verileri kullanılarak hazırlanmıştır.

\section{KAYNAKLAR}

Akgöze F (2015) Biyomimikri: Doğanın Tasarımı. https://medium.com/sherpa-blog-bulten/biyomimikrido\%C4\%9Fan\%C4\%B1n-tasar\%C4\%B1m\%C4\%B1-18e89673b445 (Erişim Tarihi: 28.08.2015)

Ali El-Zeiny RM (2012) Biomimicry as a Problem Solving Methodology in Interior Architecture. ASEAN Conference on EnvironmentBehavior Studies. Procedia Social and Behavioral Science 50, Bangkok, Tayland

Altınkaynak Ç (2016) Acil Durum Barınak Tasarımı, Gereklilikleri Ve Bu Alanda Origaminin Yeri. Yüksek Lisans Tezi, İstanbul Teknik Üniversitesi Fen Bilimleri Enstitüsü, İstanbul.

Altun Ş (2011) Doğanın İnovasyonu-İnovasyon İçin Doğadan İlham Al. Elma Yayınevi, Ankara.

Anonim (1993) Büyük Larousse Ansiklopedisi, Librairie Larousse, Interpress Yayıncılık, Cilt 18, İstanbul.

Aziz MS, El Sherif AY (2015) Biomimicry as an approach for bio-inspired structure with the aid of computation, Alexandria Engineering Journal, 55: 707-714.

Baumeister D (2013) Biomimicry Resource Handbook. A Seed Bank of Best Practices. Missoula, Montana, ABD.

Benyus JM (1998) Biomimicry, Innovation Inspired By Nature, William Morrow and Company Inc., New York, ABD.

Benyus JM (2002) Biomimicry: Innovation Inspired by Nature, Perennial, New York, ABD.

Boğa M (2013) Tasarımda Doğal Analoji: Endüstri Ürünleri Tasarımı Öğrencilerinin Yaklaşımı Üzerine Bir Çalışma. Yüksek Lisans Tezi, İstanbul Teknik Üniversitesi Fen Bilimleri Enstitüsü, İstanbul.

Eryılmaz H (2015) Biyomimikri ve Ergonomi:Tasarımda Doğadan Yenilikçi İlham. Süleyman Demirel Üniversitesi Mühendislik Bilimleri ve Tasarım Dergisi, 3(3): 469-474.

Helms M, Swaroop SV, Goel AK (2009) Biologically inspired design: Processs and product, Elsevieir, 30: 606-622.

Karabetça AR (2015) Doğadan Esinlenmiş Tasarımlar: Tasarım Stratejisi Olarak Biyomimikri. MSGSU 4. Ulusal iç Mimarlık Sempozyumu, Mekan Tasarımında Disiplinlerarası Yaklaşımlar, 6-8 Mayıs 2015, ìstanbul.

Kaya LG, Yücedağ C, Aşıkkutlu HS (2018) Reflections of Biomimicry to Spatial Design, ECSAC 2018, European Conference on Science, Art and Culture, 19-22 April 2018, Antalya.

Kennedy S (2004) Biomimicry/biomimetics: General Principles and Practical Examples. The Science Creative Quarterly. http://www.scq.ubc.ca/biomimicrybimimeticsgeneral-principlesand-practical-examples/ (Erişim Tarihi: 17.04.2018)
Knight W (2001) Beetle fog-catcher inspires engineers. New Scientist, 13: 38.

Öztoprak Z (2018) A biomimetic perspective on (retro) fitting of building envelopes, PhD. Thesis, Middle East Technical University, The Graduate School of Natural and Applied Sciences, Ankara.

Parker AR, Lawrence CR (2001) Water capture by a desert beetle. Nature, 414: 33-34.

Primlani RV (2013) Biomimicry: On the Frontiers of Design. XIMB Journal, 10: 139-148.

Ravilious K (2007) Borrowing from Nature's Best Ideas, The Guardian, July 31.

Rosemond AD, Anderson CB (2003) Engineering Role Models: Do NonHuman Species have the Answers?, Ecological Engineering, 20: 379-387.

Sey Y, Tapan M, Kanoğlu A (1987) Afet Sonrası Barınma ve Geçici Konut Tipi Araştırması. İstanbul Teknik Üniversitesi, Akademik Çalışma, İstanbul, Türkiye

Tokman L (2012) Mimarlık Üzerine Bir Bilimsel Araştırma: Tasarım, Yöntem, Uygulama. Elif Yayınevi Yayınları, Ankara, Türkiye

URL-1 (2016) Mimarlıkta Benzetme Yaklaşımı. https://slideplayer.biz.tr/slide/3307979/ (Erişim Tarihi: 17.11.2018)

URL-2 (2018) Biyomimikri nedir? https://toolbox.biomimicry.org/introduction/, (Erişim Tarihi: 25.09.2018)

URL-3 (2015) Kunduz. https://www.thecanadianencyclopedia.ca/en/article/beaver, (Erişim Tarihi: 21.02.2019)

URL-4 (2019) CH2: Avustralya'nın En Çevreci ve Doğa Dostu Binası. https://www.enteresan.com/ch2-avustralyanin-en-cevreci-vedoga-dostu-binasi, (Erişim Tarihi: 21.02.2019)

URL-5 (2019) Lloyd Crossing Sürdürülebilir Tasarım Planı. http://www.aiatopten.org/node/159, (Erişim Tarihi: 03.01.2019)

URL-6 (2012) Armadillo. http://biomimicrykth.blogspot.com/2012/02/armadillo.html, (Erişim Tarihi: 10.02.2019)

URL-7 (2016) Armadillo- Hatu Hanı. http://sancak0660ts.blogspot.com/2016/06/armadillo-tatuhayvan.html, (Erişim Tarihi: 15.02.2019)

URL-8 (2016) Long-nosed Armadillos, Rolling into a ball for protection, https://asknature.org/strategy/rolling-into-a-ball-for-protection2/\#.XD-bgzAzblU, (Erişim Tarihi: 23.02.2019)

Vincent JFV, Bogatyrev O, Pahl A-K, Bogatyrev NR, Bowyer A (2005) Putting Biology into TRIZ: A Database of Biological Effects. Creativity and Innovation Management, 14: 66-72.

Volstad NL, Boks C (2012) On the Use of Biomimicry as a Useful Tool for the Industrial Designer. Sustainable Development, 20(3): 189199.

Zari MP (2007) Biomimetic Approaches to Architectural Design for Increased Sustainability. School of Architecture, University of Victoria, Yeni Zelanda

Zari MP, Storey J (2007) An ecosystem based biomimetic theory for a regenerative built environment. Lisbon Sustainable Building Conference, SB07, 12-14 September 2007, Lisbon. 